\title{
A RELAÇÃO ENTRE O PÚBLICO E O PRIVADO: UM ESTUDO INICIAL NO PENSAMENTO DE HaNNAH ARENDT*
}

\author{
Soraya Vieira Santos, \\ da Universidade Federal de Goiás
}

\begin{abstract}
Resumo: Este artigo visa discutir, de forma introdutória, a relação entre o público e o privado a partir do pensamento de Hannah Arendt. Essa discussão é importante na medida em que, contemporaneamente, a distinção entre a esfera pública e a esfera privada tende a ficar subsumida, de modo que o privado aparece como se fosse público e o público, como se fosse privado. Assim, na impossibilidade de compreensão do público e do privado, desaparece a possibilidade da política, como capacidade de romper com o imediato, e emerge o social.
\end{abstract}

Palavras-Chave: Esfera pública. Esfera privada. Hannah Arendt.

Quanto mais completamente a sociedade moderna rejeita a distinção entre aquilo que é particular e aquilo que é público [...] quanto mais ela introduz entre o privado e o público uma esfera social na qual o privado é transformado em público e vice-versa, mais difíceis torna as coisas para suas crianças [...]. (ARENDT, 2007)

Hannah Arendt, filósofa que está no centro de grandes polêmicas do século $\mathrm{XX}$, afirma que o processo que levou à perda da autoridade, da religião e da tradição é equivalente à perda do fundamento do mundo, de modo que "todas as coisas, a qualquer momento, podem se tornar praticamente qualquer outra coisa" (ARENDT, 2007, p. 132). A autora critica duramente a perda da importância de "fazer distinções", pois, à medida que não se distinguem conceitos e "cada um de nós tem o direito de definir seus termos" (ARENDT, 2007, p. 132), deixamos de viver em um mundo comum 
em que as palavras possuem um significado preciso. Assim, conceitos como "autoridade", "liberdade" e "educação" perdem seu sentido universal para ganhar contornos de "opinião própria".

Nesse processo em que todas as coisas podem tornar-se qualquer outra coisa, ideias antes bem definidas - como "público"e "privado" - perdem seu sentido original e dissolvem-se, transformando-se em instâncias que praticamente não se diferenciam. Imersa no debate sobre o desaparecimento da esfera pública e da esfera privada, Arendt analisa que o político não pode mais sobreviver e que, como consequência, emerge o social. Na esteira de suas análises, o presente artigo busca compreender a gênese dos conceitos de público e privado, para procurar discutir em que os conceitos se converteram na contemporaneidade e quais as implicações desse processo.

\section{A GÊNESE DO PÚBLICO E DO PRIVADO NO MUNDO GREGO}

Ao iniciar suas reflexões sobre a esfera pública e a esfera privada em sua obra $A$ condição humana, Arendt $(2008$, p. 31) afirma que "todas as atividades humanas são condicionadas pelo fato de que os homens vivem juntos; mas a ação é a única que não pode sequer ser imaginada fora da sociedade dos homens". Para a autora, a ação que diz respeito à atividade que se exerce entre os homens, sem a mediação das coisas ou da matéria, "corresponde à condição humana da pluralidade, ao fato de que homens, e não o Homem, vivem na Terra e habitam o mundo" (ARENDT, 2008, p. 15). Assim, a ação se diferencia do labor, que corresponde ao processo biológico do corpo humano, e do trabalho, correspondente ao artificialismo da existência humana. ${ }^{1}$

Tendo como suposto que só a ação é exclusiva do homem, uma vez que depende da presença de outros homens, Arendt critica a tradução do conceito de Aristóteles, de zoon politikon, como animal social. Para a filósofa, a perda da ideia de animal político e a aceitação da noção de animal social revelam o esquecimento da concepção original grega de política. O conceito de homem como animal político está relacionado à vida em comum e, portanto, à ação. Segundo a autora, a capacidade de organização política - que se opõe à mera associação natural entre humanos - teve sua expressão máxima na constituição da cidade-estado, em que cada cidadão, além de sua vida privada, pertencia à vida política em que fazia uso da ação e do discurso: ${ }^{2}$

Quando, por exemplo, lemos em Aristóteles que a philia, a amizade entre os cidadãos, é um dos requisitos fundamentais para o bem-estar da Cidade, 
tendemos a achar que ele se referia apenas à ausência de facções e guerra civil. Mas, para os gregos, a essência da amizade consistia no discurso. Sustentavam que apenas o intercâmbio constante de conversas unia os cidadãos numa polis. No discurso, tornavam-se manifestas a importância política da amizade e a qualidade humana própria a ela. (ARENDT, 1987, p. 31)

O discurso referia-se ao mundo comum, em contraste com a conversa íntima em que os indivíduos falavam sobre si mesmos. Todo o pensamento político grego se baseava na divisão decisiva entre as esferas pública e privada, isso é, entre a esfera da polis e a esfera da família, entre as atividades relativas ao mundo comum e aquelas restritas à manutenção da vida. Segundo Arendt (2008, p. 38), “historicamente, é muito provável que o surgimento da cidade-estado e da esfera pública tenha ocorrido às custas da esfera privada da família e do lar". Na esfera familiar, os homens viviam juntos por causa de suas necessidades; na esfera da polis, ao contrário, estava a liberdade:"se havia uma relação entre essas duas esferas era que a vitória sobre as necessidades da vida em família constituía a condição natural para a liberdade na polis" (ARENDT, 2008, p. 40).

Como a liberdade situa-se na esfera política, caracterizava-se a polis por somente conhecer "iguais", enquanto na família encontrava-se a desigualdade.

Assim, dentro da esfera da família, a liberdade não existia, pois o chefe da família, seu dominante, só era considerado livre na medida em que tinha a faculdade de deixar o lar e ingressar na esfera política, onde todos eram iguais. É verdade que esta igualdade na esfera política muito pouco tem em comum com o nosso conceito de igualdade; significava viver entre pares e lidar somente com eles, e pressupunha a existência de desiguais; e estes, de fato, eram sempre a maioria da população na cidade-estado. (ARENDT, 2008, p. 41)

A distinção entre a esfera pública e a esfera privada era tão marcante que Arendt afirma a existência de um abismo entre elas no mundo grego. Todas as atividades - cuja finalidade se constituía na garantia da sobrevivência e no sustento do indivíduo, isso é, no seu processo vital - não eram dignas da esfera política. A vitória sobre as necessidades da vida em família é que permitiu o aparecimento da polis, pois a política não visa à manutenção da vida. Dessa forma, "no que tange aos membros da polis, a vida no lar existe em função da boa vida na polis" (ARENDT, 2008, p. 47). A excelência em si - areté para os gregos - era reservada à esfera pública, pois (não apenas a presença de outros) o partilhar da vida comum é necessário para atingi-la. 
O PÚBLICO: O MUNDO COMUM

Para Arendt, o termo"público" remete a dois fenômenos. Em primeiro lugar, significa que tudo o que vem a público pode ser visto e ouvido por todos e tem a maior divulgação possível. Nesse sentido, quando um pensamento ou um sentimento é divulgado, o privado torna-se de acesso público. Contudo, esse fenômeno é garantido pela condição de que os outros têm de partilhar a realidade do mundo e de nós mesmos:

Toda vez que falamos de coisas que só podem ser experimentadas na privatividade ou na intimidade, trazemo-las para uma esfera na qual assumirão uma espécie de realidade que, a despeito de sua intensidade, elas jamais poderiam ter tido antes. A presença de outros que veem o que vemos $\mathrm{e}$ ouvem o que ouvimos garante-nos a realidade do mundo e de nós mesmos. (ARENDT, 2008, p. 60)

No entanto, Arendt afirma que existem coisas que não podem suportar a luz implacável da constante presença de outros no mundo público. Tudo o que é considerado irrelevante para a esfera pública torna-se assunto privado, como no caso da dor física e do amor. Diz a autora:

Uma vez que a nossa percepção da realidade depende totalmente da aparência, e portanto da existência de uma esfera pública na qual as coisas possam emergir da treva da existência resguardada, até mesmo a meia-luz que ilumina a nossa vida privada e íntima deriva, em última análise, da luz muito mais intensa da esfera pública. (ARENDT, 2008, p. 61)

Em segundo lugar, o termo "público" significa o próprio mundo, posto que é comum a todos e, ao mesmo tempo, é diferente do lugar que cada indivíduo ocupa dentro dele. O mundo refere-se ao produto das mãos humanas, sendo, ao mesmo tempo, aquilo que separa e estabelece relação entre os homens: "A esfera pública, enquanto mundo comum, reúne-nos na companhia uns dos outros e, contudo, evita que colidamos uns com os outros" (ARENDT, 2008, p. 62).

A esfera pública é reservada à individualidade, pois é o lugar em que os homens podem mostrar quem realmente são. Assim, em benefício dessa possibilidade, "e por amor a um corpo político que a propiciava a todos, cada um deles estava mais ou menos disposto a compartilhar do ônus da jurisdição, da defesa e da administração dos negócios públicos" (ARENDT, 2008, p. 51). Nesse sentido, Telles afirma que

a dissolução desse espaço público significa a perda de um "mundo comum" que articula os homens numa trama visível feita por fatos e eventos tangíveis 
no seu acontecimento e que se materializa na comunicação intersubjetiva, através da qual as opiniões se formam e os julgamentos se constituem. Nesse caso, a dissolução do espaço público significa mais do que a perda de um espaço comum entre os homens. Pois essa perda significa também a dissolução do "senso comum", comprometendo esta capacidade de discernimento que a compreensão e o julgamento exigem, enquanto"maneira especificamente humana" de se fazer a experiência da realidade. (TELLES, 1990, p. 4)

Para Arendt, o problema da sociedade de massas é que o mundo perdeu a força de manter as pessoas juntas, de relacioná-las umas às outras e de separá-las. Na crítica à forma cristã de conceber a comunidade, a autora lembra que a existência de uma esfera pública - e a subsequente transformação do mundo em uma comunidade de coisas que reúne os homens e estabelece uma relação entre eles - depende da permanência:

Se o mundo deve conter um espaço público, não pode ser construído apenas para uma geração e planejado somente para os que estão vivos: deve transcender a duração da vida de homens mortais.

Sem essa transcendência para uma potencial imortalidade terrena, nenhuma política, no sentido restrito do termo, nenhum mundo comum e nenhuma esfera pública são possíveis. (ARENDT, 2008, p. 64)

O mundo comum é aquilo que encontramos ao nascer e aquilo que deixamos para trás quando morremos. $O$ público tem o sentido daquilo que transcende nossa vida e refere-se tanto ao passado como ao futuro:"É o caráter público da esfera pública que é capaz de absorver e dar brilho através dos séculos a tudo o que os homens venham a preservar da ruína natural do tempo" (ARENDT, 2008, p. 65). A dissolução da esfera pública significa a impossibilidade de uma tradição ser recriada ou estabelecida. A realidade do mundo comum não se garante pela natureza comum de todos os homens que o constituem, mas pelo fato de que todos eles estão interessados no mesmo objeto, a despeito das diferenças de posição e de perspectivas.

$\mathrm{Na}$ discussão sobre a distinção entre os conceitos de poder e de violência, Arendt (2009, p. 98) ${ }^{3}$ afirma que "esperar de pessoas que não têm a menor noção acerca do que é a res publica, a coisa pública, que se comportem de maneira não violenta e discutam racionalmente em questões de interesse não é realista nem razoável". Isso porque, quando o mundo comum é visto somente por um aspecto e por uma perspectiva, então ele acaba, pois os homens tornam-se privados de ver e ouvir os outros e privados de ser vistos e ouvidos por eles.

Esse processo, segundo Arendt, ocorre nos casos de isolamento radical, como nas tiranias, mas também nas condições da sociedade de massas 
em que os indivíduos se comportam como se fossem membros de uma única família. Nesses casos, os homens "são todos prisioneiros da subjetividade de sua própria existência singular, que continua a ser singular ainda que a mesma experiência seja multiplicada inúmeras vezes" (ARENDT, 2008, p. 67). Quando os homens são privados do espaço público - "que é constituído pela ação conjunta e a seguir se preenche, de acordo consigo mesmo, com os acontecimentos e estórias que se desenvolvem em história - recolhem-se para sua liberdade de pensamento" (ARENDT, 1987, p. 18). Acontece, portanto, uma fuga do mundo para o ocultamento da vida pública, para o anonimato.

O privado solapa o público, de forma que o que antes era visto como comum passa a ser entendido como desprovido de interesses para o outro. Por isso "não há dúvida de que é possível criar condições sob as quais os homens são desumanizados" (ARENDT, 2009, p. 81). ${ }^{4}$ A sociedade de massas destrói a esfera pública, ${ }^{5}$ ao mesmo tempo em que destrói a esfera privada, uma vez que impede a pluralidade de opiniões no espaço público comum e retira da casa e da família a possibilidade de constituição de refúgios diante do mundo.

O PRIVADO: A MANUTENÇÃO DA VIDA

O termo "privado", em sua acepção original, tem o sentido mesmo de privação. Para Arendt (2008, p. 68), ser privado da realidade significa ser destituído de coisas essenciais à vida, isso é, ser despojado da possibilidade de ser visto e ouvido por outros. Ou seja, "privado de uma relação objetiva com eles decorrente do fato de ligar-se e separar-se deles mediante um mundo comum de coisas, e privado da possibilidade de realizar algo mais permanente que a própria vida". Na ausência de outros, o homem privado não se dá a conhecer e, portanto, não existe.

A privação de relações objetivas com os outros tem levado ao fenômeno de massa da solidão:

O motivo pelo qual esse fenômeno é tão extremo é que a sociedade de massas não apenas destrói a esfera pública e a esfera privada: priva ainda os homens não só do seu lugar no mundo, mas também do seu lar privado, no qual antes eles se sentiam resguardados contra o mundo e onde, de qualquer forma, até mesmo os que eram excluídos do mundo podiam encontrar-lhe o substituto no calor do lar e na limitada realidade da vida em família. (ARENDT, 2008, p. 68)

Assim como a esfera pública desaparece na modernidade, a esfera privada, de acordo com Arendt, é também ameaçada. Por essa razão, toda a discussão sobre o privado transforma-se em discussão sobre a propriedade 
privada. A propriedade, por sua vez, é relacionada à pobreza ou à riqueza e essa interpretação é equivocada, ${ }^{6}$ uma vez que "a riqueza e a propriedade, longe de constituírem a mesma coisa, têm caráter inteiramente diverso" (ARENDT, 2008, p. 71). Para a autora, tanto a propriedade como a riqueza são historicamente de maior relevância para a esfera pública, pois essas eram a condição de admissão do indivíduo à esfera pública e à plena cidadania.

Nos tempos antigos, o indivíduo que perdia o seu lugar, a sua propriedade, perdia automaticamente a cidadania e a proteção da lei. A privatividade possuía um caráter sagrado; o lar era a esfera do nascimento e da morte, "que devia ser escondida da esfera pública por abrigar coisas ocultas aos olhos humanos e impenetráveis ao conhecimento humano" (ARENDT, 2008, p. 72). Segundo essa filósofa, não o interior dessa esfera que permanece oculta e sem o significado público, mas a sua aparência externa é importante para a cidade, posto vez que impõe os limites entre uma casa e outra. Contudo, Arendt afirma que

não é realmente exato dizer que a propriedade privada, antes da era moderna, era vista como condição axiomática para admissão à esfera pública; ela era muito mais que isso. A privatividade era como que o outro lado escuro e oculto da esfera pública; ser político significava atingir a mais alta possibilidade da existência humana; mas não possuir um lugar próprio e privado (como no caso do escravo) significava deixar de ser humano. (ARENDT, 2008, p. 74)

Como a vida pública somente era possível após o atendimento das necessidades urgentes da própria existência, a posse de propriedades significava o domínio das necessidades vitais e, portanto, a liberdade para transcender a própria existência e ingressar no mundo comum a todos:

Somente com o surgimento tangível e concreto desse mundo comum, isto é, com a ascendência da cidade-estado, pôde este tipo de propriedade privada adquirir sua eminente importância política [...]. Caso o dono de uma propriedade preferisse ampliá-la ao invés de utilizá-la para viver uma vida política, era como se ele espontaneamente sacrificasse a sua liberdade e voluntariamente se tornasse aquilo que o escravo era contra a vontade, ou seja, um servo da necessidade. (ARENDT, 2008, p. 75)

Tanto a acumulação individual de riqueza como a socialização do processo de acumulação, de acordo com Arendt, tendem a desconsiderar o sentido primeiro da propriedade. A privatividade como um todo pode ameaçar a evolução da produtividade social e, por isso, a posse privada deve ser rejeitada em benefício do crescente processo de acumulação de riqueza social. Nesse sentido, assim como a esfera pública é destituída de 
sentido nessa sociedade, a esfera privada é igualmente levada a ter novos contornos: "O fato histórico decisivo é que a privatividade moderna, em sua função mais relevante - proteger aquilo que é íntimo -, foi descoberta não como o oposto da esfera política, mas da esfera social" (ARENDT, 2008, p. 48). Assim, o privado passa a ter laços ainda mais estreitos e mais autênticos com o social, e não com o público.

\section{O SOCIAL: DILUIÇÃO DO PÚBLICO E DO PRIVADO}

A distinção entre uma esfera de vida privada e uma esfera de vida pública, segundo Arendt,

corresponde à existência das esferas da família e da política como entidades diferentes e separadas, pelo menos desde o surgimento da antiga cidadeestado; mas a ascendência da esfera social, que não era nem privada nem pública no sentido restrito do termo, é um fenômeno relativamente novo, cuja origem coincidiu com o surgimento da era moderna e que encontrou sua forma política no estado nacional. (ARENDT, 2008, p. 37)

A ascensão do social coincidiu historicamente com a transformação da preocupação individual com a propriedade privada em preocupação pública. A promoção da sociedade acontece ao mesmo tempo em que ocorre o declínio da família, que de certa forma é absorvida por grupos sociais correspondentes. $\mathrm{O}$ surgimento da sociedade de massas indica

que os vários grupos sociais foram absorvidos por uma sociedade única, tal como as unidades familiares haviam antes sido absorvidas por grupos sociais; com o surgimento da sociedade de massas a esfera do social atingiu finalmente, após séculos de desenvolvimento, o ponto em que abrange e controla, igualmente e com igual força, todos os membros de determinada comunidade. (ARENDT, 2008, p. 50)

A vitória da igualdade no mundo moderno, conforme explica Arendt (2008, p. 51), é o reconhecimento político e jurídico do fato de que a sociedade conquistou a esfera pública e que "a distinção e a diferença reduziram-se a questões privadas do indivíduo". Quanto maior é a população de qualquer corpo político, maior é a probabilidade de que o social (e não o político) constitua a esfera pública. ${ }^{7}$ Para a autora, o agrupamento de grande número de indivíduos em uma multidão possui forte inclinação para o despotismo.

Arendt (2008, p. 55) afirma que, com o triunfo da sociedade na era moderna, ocorre, inicialmente, a substituição da ação pelo comportamento 8 e, posteriormente, a substituição do governo pessoal pela burocracia, "que é o governo de ninguém". Dessa forma, 
[d]esde o advento da sociedade, desde a admissão das atividades caseiras e da economia doméstica à esfera pública, a nova esfera tem-se caracterizado principalmente por uma irresistível tendência de crescer, de devorar as esferas mais antigas do político e do privado, bem como a esfera mais recente da intimidade. (ARENDT, 2008, p. 55)

Nessa perspectiva, a ideia vigente na sociedade de massas - de homem como animal social e não animal político - ameaça a extinção da humanidade, uma vez que a sociedade tem um caráter monolítico em que "o conformismo só dá lugar a um único interesse e uma única opinião" (ARENDT, 2008, p. 55). Como prova disso, a nova esfera social transformou as comunidades em sociedade de operários, concentrados em torno da única atividade necessária para manter a vida que, para Arendt, é o labor.

Contra o crescimento constante da esfera social, a esfera pública e a esfera privada são incapazes de resistir.

[A] contradição entre o privado e o público, típica dos estágios iniciais da era moderna, foi um fenômeno temporário que trouxe a completa extinção da própria diferença entre as esferas privada e pública, a submersão de ambas na esfera do social. [...] a esfera pública porque se tornou função da esfera privada, e a esfera privada porque se tornou a única preocupação comum que sobreviveu. (ARENDT, 2008, p. 79)

No momento em que o público torna-se privado e o privado tornase público, ambas as esferas desaparecem. Arendt lembra que não apenas a extinção da esfera pública é preocupante, mas também a ausência da privatividade, na medida em que a abolição da propriedade privada significa a eliminação do lugar tangível possuído na terra por uma pessoa. Na concepção da autora, a vida privada não tem um sentido negativo, "sua discussão não é travada no sentido de desqualificar a vida privada, mas de estabelecer o seu lugar e definir as fronteiras entre duas formas distintas de existência social [...] duas formas diferentes de se fazer a experiência da sociedade" (TELLES, 1990, p. 5).

Para Arendt (2008, p. 81), aquilo que temos em particular, que usamos e consumimos diariamente, é exatamente o de que mais urgentemente temos necessidade: ${ }^{9}$

A necessidade e a vida são tão intimamente aparentadas e correlatas que a própria vida é ameaçada quando se elimina totalmente a necessidade. Pois, longe de resultar automaticamente no estabelecimento da liberdade, a eliminação da necessidade apenas obscurece a linha que separa a liberdade da necessidade. ${ }^{10}$ 
Além de suprimir a necessidade, a ausência da privatividade também retira do indivíduo o refúgio contra o mundo público comum, contra tudo o que no mundo ocorre e contra o fato de ser visto e ouvido. Nessa perspectiva, Arendt critica o pensamento de Marx:

A invasão da privatividade pela sociedade, a socialização do homem (Marx), é mais eficazmente realizada através da expropriação, mas esta não é a única maneira. Neste, como em outros aspectos, as medidas revolucionárias do socialismo ou do comunismo podem muito bem ser substituídas por uma decadência - mais lenta, porém não menos certa - da esfera privada em geral e da propriedade privada em particular. (ARENDT, 2008, p. 82)

Assim, a extinção da diferença entre a esfera privada e a esfera pública, tal como existia no mundo grego, a transferência das preocupações privadas para a política e a valorização da esfera privada como fenômeno social constituem questões a serem mais bem compreendidas e discutidas. Na perspectiva de Hannah Arendt, "a perda do espaço público significa a perda dessa condição de igualdade que apenas a liberdade pública pode construir. Excluídos ou privados desse espaço, os homens ficam fixados nas suas diferenças, enquanto forma de existência 'outorgada' pela natureza" (TELLES, 1990, p. 8). O risco desse processo está no fato de que a diferença de raça, sexo, etnia etc. - que diz respeito à esfera privada constitua critério político e, portanto, seja elemento definidor na esfera pública. ${ }^{11}$

A exigência de um espaço no qual cada ser humano possa ser julgado por suas ações e palavras - e não por sua origem ou raça - é expressa por Arendt quando defende "o direito a ter direito". Nesses termos, "a cidadania é considerada uma dimensão que excede o meramente formal para associar-se, de forma indissolúvel, a um tipo de ação política e de possibilidades concretas para a realização dos atributos que a definem" (CRUZ, 2009, p. 73). Segundo Lafer (1997, p. 64), na concepção de Arendt, a cidadania é concebida como o direito a ter direitos, "pois sem ela não se trabalha a igualdade que requer o acesso ao espaço público, pois os direitos - todos os direitos - não são dados (physei), mas construídos (nomoi) no âmbito de uma comunidade política".

Nesse sentido, a construção de uma esfera pública a partir de interesses privados é inviável, da mesma forma como é impossível a identificação do público com o Estado. O público é o lugar em que a virtude humana pode aparecer. Por isso, "nem a educação, nem a engenhosidade, nem o talento podem substituir os elementos constitutivos da esfera pública, que fazem dela o local adequado para a excelência humana" (ARENDT, 2008, p. 59). ${ }^{12}$ A indistinção entre o público e o privado desloca as questões pertinentes a ambas as esferas e confunde seus papéis em todas as instâncias: 
É uma peculiaridade de nossa sociedade, de modo algum uma coisa necessária, considerar a vida, isto é, a vida terrena dos indivíduos e da família, como o bem supremo; por esse motivo, em contraste com todos os séculos anteriores, ela emancipou essa vida e todas as atividades envolvidas em sua preservação e enriquecimento do ocultamento da privatividade, expondo-a à luz do mundo público. (ARENDT, 2007, p. 237)

Arendt reitera que - ao tornar indistintas as esferas do público e do privado e ao enfatizar a esfera do social - a sociedade moderna dificulta e torna incerto o futuro de suas crianças. Para ela, há "uma conexão entre a perda de autoridade na vida pública e política e nos âmbitos privados e prépolíticos da família e da escola" (ARENDT, 2007, p. 240). Isso porque, quando a autoridade da vida política e pública é removida, exige-se de todos igual responsabilidade pelos rumos do mundo, de forma que os adultos eximem-se de seu encargo perante as novas gerações. Desse modo,

o problema da educação no mundo moderno está no fato de, por sua natureza, não poder esta abrir mão nem da autoridade, nem da tradição, e ser obrigada, apesar disso, a caminhar em um mundo que não é estruturado nem pela autoridade nem tampouco mantido coeso pela tradição. (ARENDT, 2007, p. 245)

A diluição do público e privado e a consequente ascensão do social põem em risco, portanto, a própria continuação do mundo, na medida em que possui relação com a ausência da autoridade e da tradição. Por isso é relevante lembrar o papel da educação diante desse processo:

A educação é o ponto em que decidimos se amamos o mundo o bastante para assumirmos a responsabilidade por ele e, com tal gesto, salvá-lo da ruína que seria inevitável não fosse a renovação e a vinda dos novos e dos jovens. A educação é, também, onde decidimos se amamos nossas crianças o bastante para não expulsá-las de nosso mundo e abandoná-las a seus próprios recursos, e tampouco arrancar de suas mãos a oportunidade de empreender alguma coisa nova e imprevista para nós, preparando-as em vez disso com antecedência para a tarefa de renovar um mundo comum. (ARENDT, 2007, p. 247)

A educação que não abre mão da autoridade e da tradição possibilita, portanto, a continuidade do mundo e, quiçá, a construção de um mundo comum em que a privatividade também exista e o social não se constitua como funcional. Assim, toda a discussão de Arendt não tem o sentido de confirmação da realidade, mas traz a perspectiva da revolução e, por conseguinte, de transformação. Daí a necessidade de aprofundar a discussão em torno dessa problemática, tarefa que se impõe para estudos futuros em torno do pensamento de Hannah Arendt. 
THE RELATIONSHIP BETWEEN THE PUBLIC AND THE PRIVATE: AN INTRODUCTION TO THE THINKING OF HANNAH ARENDT

ABSTRACT: This article sets out to undertake an initial discussion of the relationship between the public and the private in the thinking of Hannah Arendt. This discussion is of utmost importance nowadays since the distinction between public and private spheres tends to be subsumed, to the extent that the private seems to be public and vice versa. Thus, given this impossibility of understanding what is public and what is private, politics as the ability to see beyond the immediate disappears and the social emerges.

KEY WORDS: Public sphere. Private sphere. Hannah Arendt.

\section{NOTAS}

1. Sobre os conceitos de labor, trabalho e ação, ver as seções III, IV e V de $A$ condição humana (ARENDT, 2008).

2. Telles (1990, p. 6) explica que ação exige a palavra para que sua obra se complete no mundo, pois, como ação, precisa do testemunho dos outros para que ganhe significado na construção de um mundo plenamente humano.

3. Sobre a distinção entre os conceitos de poder, vigor, força, autoridade e violência, ver a obra Sobre a violência. Para Arendt (2009, p. 67), "jamais existiu governo exclusivamente baseado nos meios da violência", pois o governo se baseia no poder, que emerge onde as pessoas agem em concerto, de modo que a violência aparece onde e quando o poder está em risco. Ver ainda a discussão de Habermas (2001) sobre o conceito de poder em Hannah Arendt.

4. Nessa perspectiva, Arendt (1987, p. 29) questiona: "quanta realidade se deve reter mesmo num mundo que se tornou inumano, se não quisermos que a humanidade se reduza a uma palavra vazia ou a um fantasma? Ou, para colocá-la de outra forma, em que medida ainda temos alguma obrigação para com o mundo, mesmo quando fomos expulsos ou nos retiramos dele?"

5. Para Arendt (1987, p. 69), o significado mais profundo do âmbito público se estende muito além do que entendemos comumente por vida política.

6. Hannah Arendt critica o ponto de vista de Marx sobre essa questão.

7. Segundo Arendt (2008, p. 52), os "gregos, cuja cidade-estado foi o corpo político mais individualista e menos conformista que conhecemos, tinham plena consciência do fato de que a polis, com sua ênfase na ação e no discurso, só poderia sobreviver se o número de cidadãos permanecesse restrito".

8. Nesse sentido, Arendt critica as chamadas "ciências do comportamento" que visam reduzir o homem como um todo, em todas as suas atividades, ao nível de um animal que se comporta de maneira condicionada. 
9. Para ratificar essa ideia, Arendt (2008, p. 81) lembra a passagem em que Locke afirma que, sem a propriedade, "de nada nos vale o comum".

10. Mas "embora a distinção entre o privado e público coincida com a oposição entre a necessidade e a liberdade, entre a futilidade e a realização e, finalmente, entre a vergonha e a honra, não é de forma alguma verdadeiro que somente o necessário, o fútil e o vergonhoso tenham o seu lugar adequado na esfera privada" (ARENDT, 2008, p. 83).

11. Nesse sentido, são elucidativas as análises de Arendt sobre a questão dos judeus.

12. É importante destacar que, para Arendt (2007, p. 225), "a educação não pode desempenhar papel nenhum na política, pois na política lidamos com aqueles que já estão educados".

\section{REFERÊNCIAS}

ARENDT, H. Homens em tempos sombrios. Trad. Denise Bottmann. São Paulo: Companhia das Letras, 1987.

ARENDT, H. Entre o passado e o futuro. Trad. Mauro W. Barbosa. 6. ed. São Paulo: Perspectiva, 2007.

ARENDT, H. A condição humana. Trad. Roberto Raposo. 10. ed. Rio de Janeiro: Forense Universitária, 2008.

ARENDT, H. Sobre a violência. Trad. André Duarte. Rio de Janeiro: Civilização Brasileira, 2009.

CRUZ, J. A. da. O movimento social e a escola: da criação passada à invenção necessária. EccoS, São Paulo, v. II, n. I, p. 57-75, jan./jun., 2009.

HABERMAS, J. O conceito de poder de Hannah Arendt. In: Habermas. São Paulo: Ática, 2001. (Coleção Grandes Cientistas Sociais) v. 15.

LAFER, C. A reconstrução dos direitos humanos: a contribuição de Hannah Arendt. Estudos Avançados, São Paulo, v. 11, n. 30, p. 55-65, 1997.

TELLES, V. S. Espaço público e espaço privado na constituição do social: notas sobre o pensamento de Hannah Arendt. Tempo Social, São Paulo, v. 2, n. 1, 1990.

SORAYA VIEIRA SANTOS é doutoranda do Programa de PósGraduação em Educação pela UFG e professora da Faculdade de Educação da UFG.

E-mail: soraya_vieira@hotmail.com 